PLEASE NOTE! THIS IS SELF-ARCHIVED VERSION OF THE ORIGINAL ARTICLE

To cite this Article: S. Luojus, S. Kauppinen, J. Lahti, L. Tähtinen (2017) FORMING MULTIDISCIPLINARY MASTER'S DEGREE STUDENT TEAMS BY MEANS OF GAMIFICATION CASE: THE WELIVE DESIGN GAME, ICERI2017 Proceedings, pp. 1665-1673.

doi: $10.21125 /$ iceri.2017.0517

URL: https://library.iated.org/view/LUOJUS2017FOR 


\title{
FORMING MULTIDISCIPLINARY MASTER'S DEGREE STUDENT TEAMS BY MEANS OF GAMIFICATION CASE: THE WELIVE DESIGN GAME
}

\author{
Satu Luojus ${ }^{1}$, Sami Kauppinen ${ }^{1}$, Janne Lahti', Lassi Tähtinen ${ }^{1}$ \\ ${ }^{1}$ Laurea University of Applied Sciences (FINLAND)
}

\begin{abstract}
New innovations arise as a result of dialogue between multidisciplinary design team and end users. Interaction among designers and users, where the most collaborative and descriptive methods and tools are used to achieve common understanding, can be regarded as an essential part of a highquality design process. The service design approach has been widely disseminated and rapidly adapted among designers, because the service design methods and tools have proven to be very powerful in bringing users and the service experience into the focus of service development process. Open innovation approach that utilize service design methods can be seen as an extension of service design approach which involves a broader group of stakeholders (e.g. academia) into the innovation process.
\end{abstract}

Research and development (R\&D) projects are not organised by distinctly categorized disciplinarians. Usually competences of various disciplines are needed. Creation of multidisciplinary project teams is one of Laurea's (Laurea University of Applied Sciences) main objectives when integrating higher education teaching and R\&D projects. Forming teams of students with different educational backgrounds, and familiarizing them with new complex concepts requires finding creative and effective pedagogical methods and tools.

The pedagogical starting point for integrating higher education teaching and R\&D projects is a pedagogical model, Learning by Developing (LbD), that is based on learning through research and developing. Expertise and experiences are shared between teachers and multidisciplinary student teams as well as project partners and other stakeholders. While working in the project teams, students take part as equal partners bringing their expertise with them. The teacher members of the project team take part by providing their expertise to steer the progress of the work and, at the same time, the progress of learning.

Design is a social process of achieving consensus among participants with different backgrounds and interests. Design games is a service design method that aims at inspire and help facilitating design process. The aim of the design games is to create a forum for the meeting of designers and users as well as provide tools for making their empirical tacit knowledge visible. This paper introduces design game method that aims to help multidisciplinary students in co-design workshops to create their common perspective to the design challenge, as well as to innovate and to develop more concrete and detailed digital service concepts.

Originally the WeLive design game was created for the WeLive project. WeLive applies the service design approach to deliver next generation personalised digital services to citizens. The WeLive design game was used and evaluated in twelve workshops and in total 233 students took part. The design game provided a practical introduction to the project and helped students to forming a design team.

The results highlight that the Welive design game is an excellent tool to involve students to the collaborative innovation process and ease their abilities to understand new complex concepts (e.g. open data) and form coherent digital service concepts in relatively short time. According to our experience design games seem to be in appropriate method when the objectives are: (1) to make tacit knowledge visible through joint activity, (2) to create shared understanding within a team, and (3) support group learning. In addition, design games provide a forum for the dialogue of multidisciplinary design team and end users.

Keywords: collaborative innovation, design games, shared understanding, multidisciplinary students, 


\section{INTRODUCTION}

Baregheh et al. [2] defines innovation as follows: "Innovation is the multi-stage process whereby organizations transform ideas into new/improved products, service or processes, in order to advance, compete and differentiate themselves successfully in their marketplace". Sorensen and Torfing [26] describe innovation as a learning-based activity that enable irregular intervals to discover something novel. In general, the world around us is rapidly changing and it is important for all organizations to improve their innovation capability in order to respond challenges but also utilize possibilities to develop new services and products.

The research on innovation processes has evolved from in-house and sequential activity into more open and iterative multi-actor activity. An open innovation approach presented by Chesbrough [10], starts with the idea, in which new service and product ideas moves out from companies' R\&D departments and correspondingly back in from other companies, research institutes, universities and end-users. Open innovation approach enables companies to utilize external expertise and knowledge that aim to foster their innovation capability in order to successfully respond to customers' needs. Berkhout et al. [36] described an innovation process as a circle that has no fixed starting or ending point. Blank [3] presents innovation process as an iterative process that support rapid planning, development and evaluation. Indeed, new innovations arise often as a result of dialogue between multidisciplinary design team and end-users. Interaction among designers and end-users, where the most collaborative and descriptive methods and tools are used to achieve common understanding, can be regarded as an essential part of a high-quality innovation process.

Innovation process in public sector requires extensive collaborative interaction between citizens but also different stakeholders like public and private actors, politicians, experts, private firms, civil servants, different user groups, interest organizations, universities, and community-based associations [8]. In recent years, a number of non-profit organizations have opened their innovation process by incorporating the idea of a collaborative innovation paradigm [7]. However, it is a challenge for public bodies how to organize and facilitate multi-actor collaboration. The collaboration between different actors needs either physical or virtual innovation platforms that enable participation for different actors, support the knowledge transferring among participants and foster the creation of new public service innovations.

Finally, service design approach has become popular among practitioners innovating solutions to both private and public sector during the past ten years [1]. Service design is combining management, marketing and design and is able to work as a platform between the organizations and customers. [19]. Collaborative innovation platform that utilize service design methods can be seen as an extension of service design approach, which enable to involve an extensive group of stakeholders (e.g. academia) into the multi-actor innovation process.

This paper describes a study in which multidisciplinary student groups used the WeLlve design game to team up, to build a shared understanding of the design challenge and to create a design solution in limited time. The aim of the study was to evaluate the suitability of "the WeLive design game", as a mediating tool for creating shared understanding within the collaborative innovation process.

\section{SHARED UNDERSTANDING IN DESIGN TEAMS}

The digital revolution has raised new challenges for designing services. At the same time, while services have become the most important economic power in the world [21] the nature of services and the pace of change have shifted dramatically. Services have evolved multichannel services where digital technology plays a significant role.

According to Runhaar et al. [24] teams are better than individuals in managing complex problems and in dealing with ever-changing demands. Thus, the implementation of team-based structures is regarded as an effective way to support organizations to become reflexive and flexible entities. [11, 32]. The effectiveness of teams is contingent on how team members learning together and developing a shared understanding of the complex problems they are dealing with [30, 31]. This, in turn, regards teams to develop a shared understanding of the complex problems they are confronted in order to find effective ways to deal with those problems. [24, 29].

Because the role of teamwork in organizations has increased $[12,17]$ it is critical for higher education to provide multidisciplinary students not only with competence to be effective collaborators and team learners themselves, but also with tools for supporting team work. This kind supportive tools can be 
used to help another collaborators express themselves and to ease their abilities to perceive new complex concept more quickly.

\subsection{Design team}

Goodwin [35] defines design as "the craft of visualizing concrete solutions that serve human needs and goals within certain constraints." She explains her definition as follows: (1) visualizing concrete design solutions is the essence of design. These solutions could be tangible products or services that are intended to provide a specific sort of experience. What designers must excel at is looking at a blank surface and filling it with believable representations of a design solution so that other people can see, understand, and finally build it. (2) Design can be seen as a craft because it is neither science nor art, but somewhere in between. Design, while it is informed by scientific learning (e.g. about human senses, cognition, and ergonomics), focuses on understanding only to the extent that is necessary to solve the design challenge. On the other hand, design is not about expressing the inner vision of the designer, but it is very much about creation. (3) Design must serve human needs and goals. Good design helps humans accomplish their goals in an efficient, effective, safe, and pleasant way. At the same time, design seeks for simple functionality, but pleasure and aesthetic satisfaction are also important human goals. (4) Design always happens within certain constraints. For example time and cost are always factors on even the most ambitious design projects. [35].

The design team conducts design research with potential end users, customers, and other stakeholders. It identifies needs and wants based on that research, and determines the design solutions that will address those needs and wants within the constraints. In order to ensure team members learning together and creating a shared understanding, the ideal design team is small enough to keep communication overhead to a minimum but large enough to incorporate the required skills and to ensure that no individual designer's blind spot go unexamined. [35].

\subsection{Creating shared understanding within design team}

When forming teams the cultural differences and different educational backgrounds could cause misunderstanding (i.e. the design practices, negotiation habits, decision-making processes, etc.). However, multidisciplinary teams have a lot of tacit knowledge. Making tacit knowledge visible helps not only to create a shared understanding, but also enriches creative and innovative team work. Tacit knowledge could be made visible in an environment where feelings, experiences and images can be shared with others. Tacit knowledge can be communicated through joint activity. According to Nonaka and Konno [20] "Ba" can be understood as a platform for creating shared understanding. They highlights, that dialogue is the key. Susceptibility in understanding what others mean and their meanings as well as willingness to bring tacit knowledge visible are required. [20].

In order to create shared understanding in a design team Boujut [6] suggests to use a mediating tools, the so-called "mediating object". The key components of media-tion are the subject, object and mediational artefact $[34,35]$. The use of tools is related to mediated activity. Activities are directed to an object, and the goal is to reach a final result by shaping the object. In this case the mediating tool is the concrete design game. When a design game is taken as part of the activity (i.e. team work), it influences the way how the intention becomes concrete in the object of the activity and the functional environment; changes of activities often cause changes in the physical environment. The design game can be seen as a mediating tool for reaching the final result: for making tacit knowledge visible through joint activity and thus, for creating shared understanding within the design team.

\subsection{Design games}

According to Erickson [13] design is a social process to achieve consensus among participants with different backgrounds and interests [13]. An essential element in the co-design approach is that the participants can surpass their own limits and examine the current issue from alternative perspectives. Co-design workshops are usually identified by the volitional nature, creative engagement and outcome, and the quite specific application to design research. By invitation, users and other stakeholders engage in the generation or manipulation of visual artifacts to convey their contemplations or ideas. [15, 18].

To enhance the creativity and to encourage the participants in a specific design context to express themselves, there are specifically designed co-design methods. These function as a support to both, the designers and the users in their creativity and interpretations during the design process. In the co- 
design workshops, the participants produce as graphically as possible illustrated ideas and reflections to support the design process. Consequently, these methods typically produce visual and verbal knowledge to delineate and discover design opportunities. [18]. Design games, as one of the methods, is a game-based approach. Salen and Zimmerman [25] appoint that "a game is a system in which players engage in an artificial conflict, defined by rules, that results in a quantified outcome."

"Design game" concept lacks a general definition, but instead, various descriptions for the concept's characteristic exist. In most descriptions are about staging participation and rarely competitive in terms of winning the game, and the design moves are guided by rules and tangible game pieces. According to Brandt's [4] list of the design game characteristics: they have open tasks that allow the participants to make their own interpretations and find meaningful focus. The games are engaging, create a relaxed and informal atmosphere that increase creativity and utilize different senses. They include ambiguous and open-ended props forcing the participants to be explicit in describing their understanding and interpretation about them, and they provide a shared design language. [4].

Vaajakallio [28] appoints three common attributes of design games in a co-design process: (I) Design games create a common design game language. The game material is equivocal and fragmented, which (a) helps players to be explicit in their choices and understanding, and b) supports shared understanding of the topic by giving space for personal insights, comments and ideas. (II) The games promote a creative and explorative attitude by the tangible material and the generative, sensitive, visual and playful tools aim to sensitize the imagination and facilitate exploration in a co-design setting. (III) The games facilitate the participants to envision and enact to hypothetical cases. The focus is on finding design opportunities instead of explaining a phenomenon in detail. [28].

Design games aim to inspire design and help facilitation of a co-design process. The distinctive difference between design games and ordinary games is that, design games are not about winning or losing. However, they could include playing pieces like cards, game boards and rules, but the essential element and the main goal is to explore and try out various aspects of design. The playing pieces are usually based on data from previous gathering like surveys, interviews, observation or ethnography. In a case, that the earlier studies cover a large user group, a design game may be utilized to focus on a smaller one. Usually 4-6 participants form the design game group to generate ideas and design concepts. The design game can be used to gain a deeper understanding of user insights and to co-design ideas to correspond with users' and other stakeholders' proposals. [4, 28].

\section{FROM MULTIDISCIPLINARY STUDENT GROUPS TO DESIGN TEAMS}

Research and development (R\&D) projects are not organized by distinctly categorized disciplinarians. Usually competences of various disciplines are needed. Creation of multidisciplinary project teams is one of Laurea's (Laurea University of Applied Sciences) main objectives when integrating higher education teaching and R\&D projects.

\subsection{LbD-based pedagogy and Cooperative learning}

The pedagogical starting point for integrating higher education teaching and R\&D projects in Laurea (Laurea University of Applied Sciences) is a pedagogical model, Learning by Developing (LbD). LbD is based on learning through research and developing. The typical characteristics of LbD include authenticity, partnership, experiential nature, creativity and a research-oriented approach [23]. Expertise and experiences are shared between teachers and multidisciplinary student teams as well as project partners and other stakeholders. While working in the project teams, students take part as equal partners bringing their expertise with them. The teacher members of the project team take part by providing their expertise to steer the progress of the work and, at the same time, the progress of learning.

Johnsons' ideas support the basic ideas of LbD. The five main elements of The Johnsonian model of cooperative learning can be seen as essential part of student team work. Those elements are: 1) positive interdependency to achieve a common goal, 2) individual accountability for doing his or her share of work, 3) face to face interaction, 4) learning of social skills such as decision-making and communication and 5) following and evaluating team processes. In cooperative learning everyone has to support each other, since teams have a common goal that no individual can achieve alone. [16]. It is also notable, that studies of cooperative learning suggest that involvement in cooperative learning is a strong predictor of a student's academic performance in class [27]. 
In service design studies, the learning process follows the future-oriented design process. The multidisciplinary student groups develop their competence by producing new digital service concepts in design teams. Learning is a way of creating new knowledge and competence that links learning to innovation activities. Forming teams of students with different educational backgrounds, and familiarizing them with new complex concepts requires finding creative and effective pedagogical methods and tools. In the next chapter, we will elaborate the WeLive design game that we have used as a tool for creating shared understanding and for group learning.

\subsection{Multidisciplinary student teams learn by designing}

The WeLive design game was created for the WeLive project in the spring of 2015. The objective of the WeLive project is to transform the administration-centered model of designing public digital services into a new kind of collaborative innovation process which enables the participation of citizens, companies, academia and public actors. The project aims to make extensive use of service design methods, which enable different actors to participate together in defining and developing digital services as well as creating business. In addition, the project endeavors to harness open data that has been accumulated by public administration, organizations, companies and private citizens into new service innovations co-created by various actors.

The background material for the WeLive design game was collected by way of a survey in the spring of 2015. In total 307 people from the Capital Region of Finland took part in the survey. The collected data was analyzed and "persona cards" and "needs cards" were designed for the game based on the analysis. The persona cards give basic information about the citizens for whom the digital services will be designed. The needs cards give information about citizens' needs and wants related to digital services. In addition, "information resource cards" were designed, which give information about existing open data assets. Information about existing open data was gained from Helsinki Region Infoshare, which publishes open data that Finnish cities have. The game board (fig. 1) brings the cards together and provides the space for the description of a new digital service. The objective of the WeLive design game was to help participants to team up, to create shared understanding, and to create more concrete and detailed digital service scenarios based on the needs and ideas revealed in the web-based survey research.

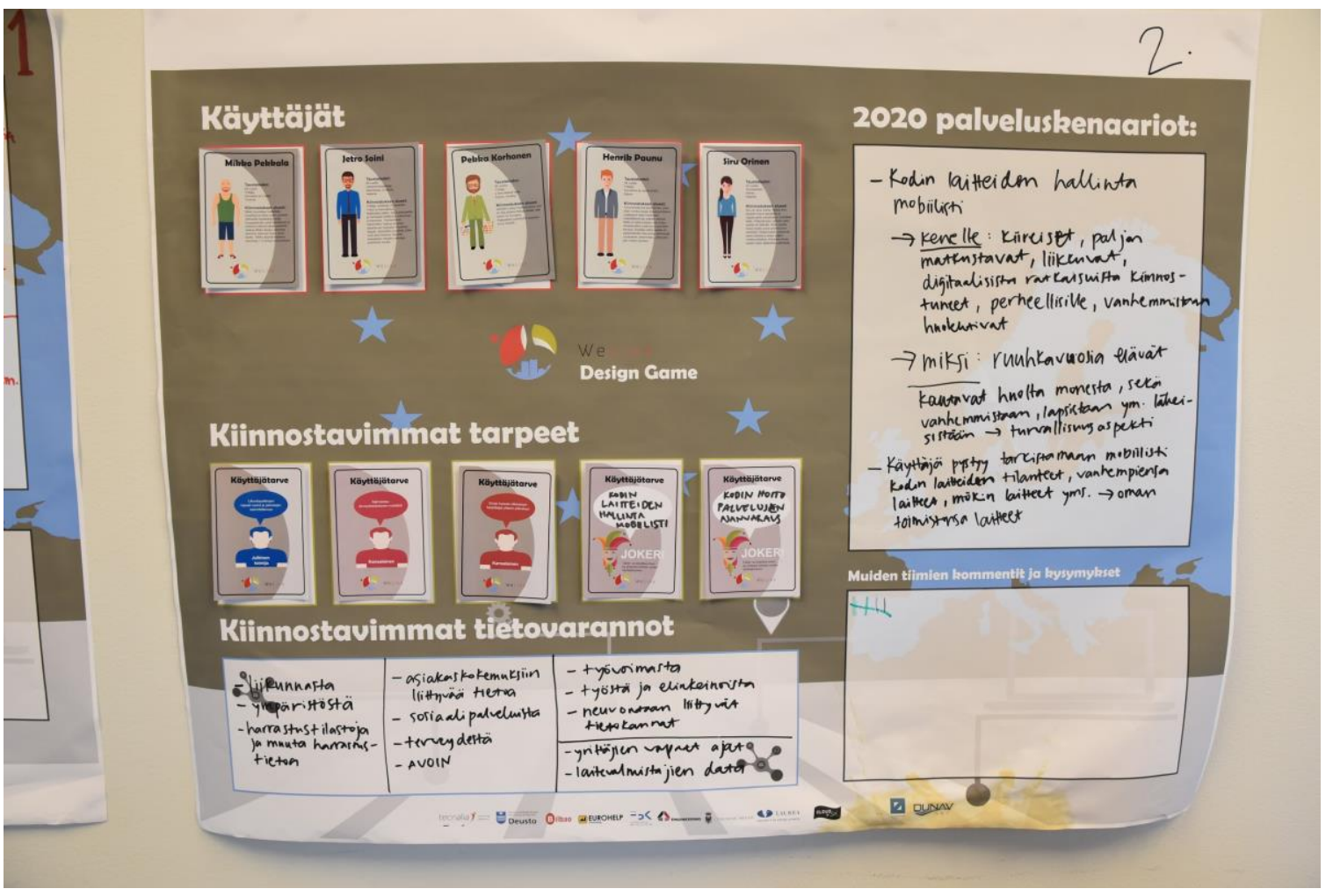

Figure 1. Design Game Board 
The duration of the design game were about two and a half hours. The participants of the design game were divided into groups of 3-5. In the beginning, the facilitator introduced background of the project and the goal of the game in short. The game session consisted of five phases, which are the following: 1) The teams chose five users for whom they wanted to design new kinds of digital services. 2) The teams chose three of the most interesting user needs as a basis for developing service ideas. They were also asked to come up with two more needs and write them on empty cards. 3) The teams were asked to give textual descriptions of their service ideas on a poster. The ideas were described briefly one at a time (what is the idea, who uses it, why and how) and finally the team selected the best idea. 4) The teams were asked to describe the best idea from the user's perspective with a short scenario, in other words how the user will use the service. 5) Finally, the participants presented the ideas and voted which one was the best.

\section{RESULTS AND DISCUSSION}

The aim of the study was to evaluate the suitability of "the WeLive design game", as a mediating tool for creating shared understanding within the collaborative innovation process. The design games were played in a student teams, while the facilitator and two other researchers made observations about the design game process and the participants expressions. Later the participants were also asked to give feedback on the design game session as well as the design game itself. The findings are based on iterative evaluation process, where the game sessions was evaluated in twelve workshops, in where total 233 multidisciplinary Master's degree students took part, on student feedback, and on analyzing students' learning outcomes.

The main results from the evaluation of the WeLive design game workshops with students can be seen in below (Table 1). It shows that the Design Game helped student teams to design/innovate new digital services as a part of the collaborative innovation process. The Design Game guided students immediately to think about digital services and more importantly, what are the citizens' needs related to the future public digital services.

The WeLive design game, like games generally, makes use of playing cards, game boards, and other gamified elements that created a favorable design environment that was noticed to motivate student players to utilize design thinking/creative thinking. Furthermore, we recognized that favorable relaxed atmosphere in innovation ideation empowered design teams' confidence and spirit in their prior knowledge; e.g. the design game encouraged participants immediately beginning of the study course to dive into innovate digital services solutions, without knowing their final outcome of the innovation. With help of the favorable atmosphere students were able to discuss and share their thoughts about citizens' needs and form a common vision about digital public service ideas with fellow students.

It is important that learning process involves students to form design teams and gives a concrete experience in the beginning of the study course. The WeLive Design Game further improved the learning process by providing students an actively inclusive learning situation in which they can link their own or team member prior knowledge to new one. Moreover, higher education students, who have been working at least three years, gained knowledge during the game session that they managed to integrate into their subject learning process.

The game rules defined an operational structure for the innovation process, which determines the objectives of the design, and feeds the design process by bringing new perspectives and dimensions systematically to various stages of the design game process. The rules enable teachers in different courses an easy way to explain the objectives of the design game process for the student participants in a guided manner. The Design Game rules created clear steps, (1) from choosing personas and (2) their needs (3) to understand the open data needed, which helped students to proceed in a favorable atmosphere from one step to another. 
Table 1. Summary of the results of the study.

\begin{tabular}{|c|c|}
\hline Welve Design Game & Explanation \\
\hline $\begin{array}{l}\text { Gamified elements of } \\
\text { the Design Game }\end{array}$ & $\begin{array}{l}\text { - Created a positive atmosphere that encouraged multidisciplinary } \\
\text { students for dialog } \\
\text { - Helped students to form shared understanding of the complex problems } \\
\text { they are dealing with } \\
\text { - Encourage students to creativity and expressing their latent thoughts } \\
\text { - Help students in making tacit knowledge visible through joint activity } \\
\text { - Helps in forming collaborative groups, training students to be effective } \\
\text { collaborators, and managing collaborative groups effectively. }\end{array}$ \\
\hline $\begin{array}{l}\text { Rules of the Design } \\
\text { Game }\end{array}$ & $\begin{array}{l}\text { - Helped to introduce the design process in a systematic manner. } \\
\text { - Provided a structure to teach new concepts (e.g. open data). } \\
\text { - } \quad \text { Provided novel and up to date information (e.g. open data that is } \\
\text { - Increased the understanding of the design field and end users (e.g. } \\
\text { personas that represent different target groups). } \\
\text { - Define the objectives and the constraints for the creative ideation } \\
\text { process (e.g. the end result was a digital service concept). } \\
\text { Ensure that the objectives of design will be achieved. }\end{array}$ \\
\hline $\begin{array}{l}\text { Benefits for the design } \\
\text { team / the design } \\
\text { process }\end{array}$ & $\begin{array}{l}\text { - Makes easier to involve citizens into the design process and understand } \\
\text { their needs and wants in more systematic way. } \\
\text { - Encourage students to learning together } \\
\text { - Provided concrete experience to students }\end{array}$ \\
\hline
\end{tabular}

\section{CONCLUSIONS}

Innovations are created as a result of a dialogue between multidisciplinary design team and end users. We have noticed that a challenge in the collaborative innovation process is finding methods and ways of working that familiarize the students with new complex concepts and making their tacit knowledge visible. In addition, forming teams of Master's students with different educational backgrounds, and familiarizing them with new complex concepts requires creative and effective pedagogical methods and tools.

In this paper, we have presented the WeLive design game that seems to be an excellent tool for involving students into the collaborative innovation process, to ease their abilities to understand new complex concepts (e.g. open data) and to design concrete digital services in relatively short time. The WeLive design game is extensively transferable to targets outside the WeLive project and it have has been successfully used in forming groups in during different study units than actual targeted.

According to our experience design games seem to be in appropriate method when the objectives are: (1) to make tacit knowledge visible through joint activity, (2) to create shared understanding within a team, and (3) support group learning. In addition, design games provide a forum for the dialogue of multidisciplinary design team and end users. 


\section{REFERENCES}

[1] T.W. Andreassen, P. Kristensson, L. Lervik-Olsen, A. Parasuraman, J.R. McColl-Kennedy, B. Edvardsson and M. Colurcio, "Linking service design to value creation and service research," Journal of Service Management, 27(1), 21-29, 2016.

[2] A. Baregheh, J. Rowley and S. Sambrook, "Towards a multidisciplinary definition of innovation. Management decision," 47(8), 1323-1339, 2016.

[3] S. Blank, "Why the lean start-up changes everything," Harvard business review, 91(5), 63-72, 2013.

[4] E. Brandt, "Designing Exploratory Design Games: A Framework for Participation in Participatory Design?," Proceedings of the Ninth Conference on Participatory Design: Expanding boundaries in design, PDC 2006, Trento, Italy, August 1-5, 2006.

[5] J-F. Boujut and E. Blanco, "Intermediary objects as a means to foster co-operation in engineering design," Journal of Computer Supported Collaborative Work, 12(2), 205-219, 2003.

[6] J-F. Boujut, "User-defined annotations: artefacts for co-ordination and shared understanding in design teams," J. ENG. DESIGN, VOL. 14, NO. 4, December 2003, 409-419, 2003.

[7] B. Bommert, "Collaborative innovation in the public sector," International public management review, 11(1), 15-33, 2010.

[8] S. Borins, "Encouraging innovation in the public sector," Journal of intellectual capital, 2(3), 310319, 2001.

[9] H.V. Carstensen and C. Bason, "Powering collaborative policy innovation: Can innovation labs help?," The Innovation Journal, 17(1), 2, 2012.

[10] H. Chesbrough, "Open Innovation: The New Imperative for Creating and Profiting from Technology," Harvard Business School Press, Boston, MA. 2003.

[11]S. Decuyper, F. Dochy, and P. Van de Bossche, "Grasping the Dynamic Complexity of Team Learning: An Integrative Model for Effective Team Learning in Organisations," Educational Research Review 5: 111-133. 2010.

[12] A. Edmondson, "Psychological Safety and Learning Behavior in Work Teams," Administrative Science Quarterly, 44, 2, 350-383, 1999.

[13]T. Erickson, "Notes on Design Practice: Stories and Prototypes as Catalysts for Communication," In Carroll, J. (1995). Scenario-Based Design: Envisioning Work and Technology in System Development. New York: Wiley \& Sons, 1995.

[14]W. Gaver, A. Boucher, S. Pennington and B. Walker, "Cultural Probes and the value of Uncertainty," Interactions. Vol. 11 (No. 5). New York: ACM Press, 53-56, 2004.

[15]B. Hanington, "Methods in the Making: A Perspective on the State of Human Research in design," Design Issues. Vol. 19 (No. 4). Cambridge, MA: MIT Press, 9-18, 2003.

[16]D.W. Johnson and R.T. Johnson, "Learning together and alone: Cooperative, competitive and individualistic learning," New Jersey: Prentive-Hall. 1999.

[17]B. Kirkman and B. Rosen, "Beyond Self-Management: Antecedents and Consequences of Team Empowerment," Academy of Management Journal, 42, 1, 58-74, 1999.

[18] T. Mattelmäki, "Design probes," Aalto University, 2006

[19] S. Moritz, "Service Design, Practical Access to Evolving Field," KöIn International Schoolof Design, 2005.

[20] I. Nonaka and N. Konno, "The concept of "ba": Building a foundation for knowledge creation, "California management review, 40(3), 40-54, 1998.

[21] A.L. Ostrom, M.J. Bitner, S.W. Brown, K.A. Burkhard, M. Goul, V. Smith-Daniels, H. Demirkan, and E. Rabinowich, "Moving forward and making a difference: research priorities for the science of service," Journal of Service Research, 1-33, 2010.

[22] P. Prud'homme van Reine, "The culture of design thinking for innovation," Journal of Innovation Management, 5(2), 56-80, 2017. 
[23]K. Raij, "Learning by Developing in Higher Education" Journal of Education Sciences", Issue II, 621. Eötvös Loránd University, Faculty of Education and Psychology, 2013.

[24]P. Runhaar, D. ten Brinke, D.M. Kuijpers, R. Wesselink and M. Mulder, "Exploring the links between interdependence, team learning and a shared understanding among team members: the case of teachers facing an educational innovation," Human Resource Development International, 2014 Vol. 17, No. 1, 67-87, 2014.

[25]K. Salen. and E. Zimmermann, "Rules of Play - Game design fundamentals," England: the MIT press, 2004.

[26]E. Sørensen and J. Torfing, "Introduction: Collaborative innovation in the public sector," Innovation Journal, 17(1), 1-14, 2012.

[27] M. Tsay and M. Brady, "A case study of cooperative learning and communication pedagogy: Does working in teams make a difference?," Journal of the Scholarship of Teaching and Learning, Vol. 10, No. 2, June 2010, pp. 78 - 89, 2010.

[28] K. Vaajakallio, "Design games as a tool, a mindset and a structure," Aalto University publication series, Aalto University, School of Arts, Design and Architecture. 2012.

[29] P. Van den Bossche, W. Gijselaers, M. Segers, and P. A. Kirschner, "Social and Cognitive Factors Driving Teamwork in Collaborative Learning Environments. Team Learning Beliefs \& Behaviors." Small Group Research 37: 490-521, 2006.

[30] M. van Woerkom and M. A. Croon, "The Relationships Between Team Learning Activities and Team Performance." Personnel Review 38: 560-577, 2009.

[31]D. Vora and L. Markoczy, "Group learning and performance: the role of communication and faultlines." The International Journal of Human Resource Management, Vol. 23, No. 11, June 2012, 2374-2392, 2012.

[32] J.M. Wilson, P.S. Goodman, and M.A. Cronin, "Group Learning." Academy of Management Review 32: 1041-1059, 2007.

[33] L.S. Vygotski. "Mind in society: The development of higher psychological processes," Cambridge. Harvard University Press, 1978.

[34] L.S. Vygotski LS, "Ajattelu ja kieli," Espoo. Weilin + Göös, 1982.

[35] K. Goodwin, "Designing for the Digital Age: How to Create Human-Centered Products and Services," Indianapolis, IN: Wiley Publishing, Inc., Technical Communication 57(1):112-113. 2009.

[36] F. Berkhout, J. Hertin and D.M. Gann, "Learning to adapt: Organisational adaptation to climate change impacts," Springer Netherlands, 78: 135, 2006. https://doi.org/10.1007/s10584-006-9089-3 